\title{
Whole Genome Sequencing in the Management of Non-Tuberculous Mycobacterial Infections
}

\author{
Matúš Dohál ${ }^{1, *}$, Igor Porvazník ${ }^{2,3}$, Ivan Solovič ${ }^{2,3}$ and Juraj Mokrý ${ }^{1}$ (D) \\ 1 Biomedical Center Martin, Department of Pharmacology, Jessenius Faculty of Medicine, Comenius University, \\ 03601 Martin, Slovakia; juraj.mokry@uniba.sk \\ 2 National Institute of Tuberculosis, Lung Diseases and Thoracic Surgery, 05981 Vyšné Hágy, Slovakia; \\ igor.porvaznik@vhagy.sk (I.P.); solovic@hagy.sk (I.S.) \\ 3 Faculty of Health, Catholic University, 03401 Ružomberok, Slovakia \\ * Correspondence: dohal1@uniba.sk; Tel.: +42-19-0252-4199
}

Citation: Dohál, M.; Porvazník, I.; Solovič, I.; Mokrý, J. Whole Genome Sequencing in the Management of Non-Tuberculous Mycobacterial Infections. Microorganisms 2021, 9, 2237. https://doi.org/10.3390/ microorganisms 9112237

Academic Editors: Isobella Honeyborne and Giovanni Satta

Received: 30 September 2021

Accepted: 25 October 2021

Published: 27 October 2021

Publisher's Note: MDPI stays neutral with regard to jurisdictional claims in published maps and institutional affiliations.

Copyright: (C) 2021 by the authors. Licensee MDPI, Basel, Switzerland. This article is an open access article distributed under the terms and conditions of the Creative Commons Attribution (CC BY) license (https:/ / creativecommons.org/licenses/by/ $4.0 /)$.

\begin{abstract}
Infections caused by non-tuberculous mycobacteria (NTM) have been a public health problem in recent decades and contribute significantly to the clinical and economic burden globally. The diagnosis of infections is difficult and time-consuming and, in addition, the conventional diagnostics tests do not have sufficient discrimination power in species identification due to crossreactions and not fully specific probes. However, technological advances have been made and the whole genome sequencing (WGS) method has been shown to be an essential part of routine diagnostics in clinical mycobacteriology laboratories. The use of this technology has contributed to the characterization of new species of mycobacteria, as well as the identification of gene mutations encoding resistance and virulence factors. Sequencing data also allowed to track global outbreaks of nosocomial NTM infections caused by M. abscessus complex and M. chimaera. To highlight the utility of WGS, we summarize recent scientific studies on WGS as a tool suitable for the management of NTM-induced infections in clinical practice.
\end{abstract}

Keywords: whole-genome sequencing; non-tuberculous mycobacteria; diagnostics

\section{Introduction}

Non-tuberculous mycobacteria (NTM) are all species of bacteria within the genus Mycobacterium (M.), except M. tuberculosis and M. leprae; so far, more than 180 species have been identified [1]. NTM are environmental, opportunistic pathogenic bacteria and only a limited number of species cause infections that primarily affect the lungs (pulmonary disease), skin, soft tissues, lymph nodes, but are also responsible for surgical wound infections, implant-associated and catheter infections [2-4]. The pulmonary form of the disease may be manifested by hypersensitivity pneumonitis, nodular bronchiectasis, or fibrovascular disease. Infections caused by NTM have risen rapidly in recent decades, and in many developed countries, the number of cases has exceeded the incidence of pulmonary tuberculosis [5]. In addition, some species of mycobacteria are also associated with increased mortality in domestic, wild animals, or aquatic organisms, thus contributing to high economic damage and negative environmental impact [6-8].

Species belonging to the $M$. avium complex (M. chimaera, $M$. intracellulare, $M$. avium) are the most widespread globally, but species within M. abscessus complex (M. abscessus subsp. abscessus, M. abscessus subsp. boletti, M. abscessus subsp. massiliense) also pose a great threat due to high degree of resistance $[9,10]$. The increasing incidence of infections caused by NTM is associated with demographic changes, aging population, and an increasing number of patients with chronic diseases (e.g., chronic obstructive pulmonary disease, cystic fibrosis (CF), cancer, diabetes), including immunosuppressive conditions [11]. However, the disease can also occur in patients without obvious predisposition, which may be related to specific gene mutations encoding changes in the function of the immune system [12]. 
The prolonged treatment (at least 18 months) regimens of NTM infections based on the administration of the combination of several antibiotics are often associated with poor patient outcomes and cure rates ranging from $30-50 \%$ for $M$. abscessus infections to $80-90 \%$ for M. malmoense infections [13]. The lipid-rich hydrophobic cell walls of NTM are optimal for biofilm formation. These structures are effectively resistant to antimicrobial agents and allow bacterial colonies to persist on living and non-living surfaces. In addition, treatment regimens and management of clinical symptoms vary across the species of NTM, so proper identification of the causative agent is important in clinical practice [14,15].

In diagnostics of NTM, 3 or more sputum specimens from a single patient are necessary. However, due to the high risk of contamination from the microflora of the oral cavity, the diagnosis can be made from a single bronchoscopic sample or a lung biopsy [16]. In the past, NTMs have been characterized by their growth rate (slow-growers: forming visible colonies in seven or more days; rapid-growers: forming visible colonies in less than seven days) and the type of pigment produced. Rapid-growing NTM (the most clinically relevant species are $M$. chelonae, $M$. fortuitum, M. abscessus) do not produce pigment, whereas slow-growing NTM (the most clinically relevant species are M. avium complex, M. kansasii, M. marinum, M. simiae, M. haemophilum, M. xenopi) are divided into 3 groups according to the type of pigment produced: nonchromogens, photochromogens, and scotochromogens. The slow-growing NTM are more prevalent and present a higher risk of drug resistance than fast-growing ones [17]. In general, smear microscopy is the diagnostic method preferred in most clinical laboratories in countries worldwide, due to its low cost. However, the sensitivity of smear microscopy is only $60-70 \%$, and the inability to diagnose extrapulmonary forms of mycobacterial diseases significantly reduces its usefulness [18]. Despite these facts, smear microscopy and culture are still gold standards in diagnostics of mycobacteria. Traditional biochemical and immunological assays or high-performance liquid chromatography used to identify NTM are time-consuming, insensitive, therefore have been replaced by molecular methods such as line probe hybridization, polymerase chain reaction (PCR), real-time PCR, and DNA sequencing. Limitations of conventionally used 16s rRNA gene sequencing (the approved standard for identification, classification, and quantitation of microbes) include the inability to distinguish M. abscessus subspecies, as well as misidentification of $M$. chimaera as $M$. intracellulare, therefore other conserved genes are used (e.g., rpoB, $h s p 6$ and 16S-23S internal transcribed spacer). Some commercial kits, based on PCR, are available, such as AccuProbe (Hologic Inc., Marlborough, USA), INNOLiPA Mycobacteria (Fujirebio Europe, Ghent, Belgium), Speed-oligo Mycobacteria (Vircell, Granada, Spain), and GenoType NTM-DR (Hain Lifescience, Nehren, Germany), with a narrow spectrum of detected NTM species and limited sensitivity and specificity [19].

The whole-genome sequencing (WGS) method allows clinicians to overcome the limitations of the conventional tests used for the diagnosis of mycobacterial infections and better understand the global diversity of NTM species [20]. WGS can identify all single nucleotide polymorphisms (SNPs) associated with resistance, as well as phylogenetic SNPs characteristic for individual NTM species [21]. In addition, WGS also contributes to the diagnosis of mixed NTM infections associated with two or more particular species [22]. Sequencing data should be also used in molecular epidemiology analysis as they provide a detailed insight into transmission dynamics of NTM (e.g., identification of hospital outbreaks) [23]. Although WGS technology is currently not available in all clinical settings, however, the purchase price is gradually reduced, and in some reference mycobacteriological laboratories this method is implemented into routine practice for identification of mycobacteria and genotypic drug susceptibility testing of $M$. tuberculosis [24].

In this mini-review, we summarize the latest scientific publications focused on WGS as a suitable tool for the management of NTM infections.

\section{WGS Perspectives for Diagnostics and Characterization of Resistance Patterns of NTM}

The early symptoms of NTM disease are usually non-specific. Patients complain of chest pain, productive cough, shortness of breath, fatigue, and fever [25]. In clinical 
laboratories in countries with a high incidence of tuberculosis, the diagnosis of mycobacterial infections is based mainly on the culture detection of acid-fast bacilli in a sputum sample and chest radiograph (X-ray or high-resolution computed tomography findings), which complicates the differentiation of NTM from M. tuberculosis complex due to morphological similarities together with identical clinical symptoms, and can lead to incorrect and ineffective treatment regimen [26]. In this context, Advani et al. performed a WGS study on M. tuberculosis isolates and found that almost $20 \%$ of all isolates contained NTM mycobacteria, indicating coinfection [27]. Ongoing NTM infection symptoms are often non-specific and can be also misdiagnosed as chronic obstructive pulmonary disease, chest infection of unknown cause, or, more recently, COVID-19. Therefore, the correct species-level identification of pathogens is essential in clinical practice.

WGS technologies provide the possibility of taxonomic reconstruction and identification of unique families of genes occurring within the genus Mycobacteria with biomedical application in the development of new reliable diagnostic tools [1]. These data are also useful in identifying rare NTM, the clinical significance of which is greatly underestimated, because they remain unrecognized in diagnostic laboratories, highlighting the utility of WGS compared to traditional diagnostic methods [28]. In general, NTM colonies grown on solid media (e.g., Lowenstein-Jensen) or in liquid media (Middlebrook 7H9 broth) of automated incubation system (BACTEC MGIT 960 system, Becton, Dickinson and Company, Franklin Lakes, NJ, USA; VersaTREK system, Thermo Fisher Scientific Waltham, MA, USA; MB/BacT Alert 3D, bioMérieux, Marcy-l'Étoile, France) proceeded from clinical (pulmonary-sputum; extrapulmonary-blood, tissues) or environmental samples (microbiological swabs) are the most commonly used materials for diagnostic and sequencing purposes (Figure 1).

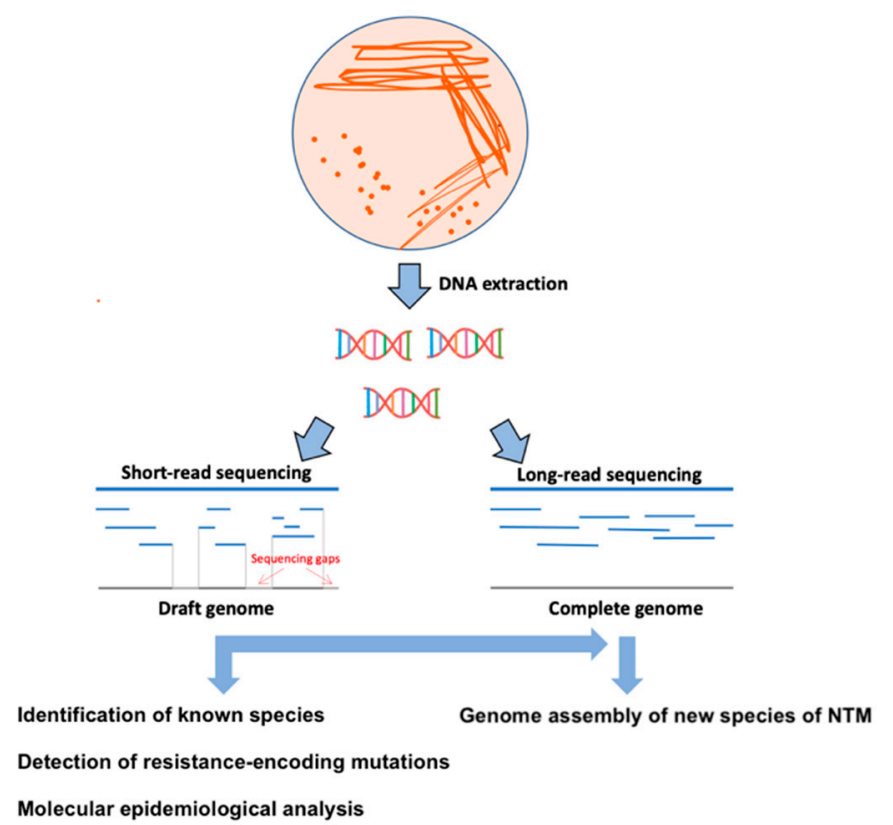

Figure 1. Schematic representation of the WGS methodological procedure. In the first step, DNA is extracted from colonies grown on a solid or liquid culture medium. Subsequently, sequencing libraries are prepared for short- or long-read sequencing. In the last step, the sequencing data are bioinformatically processed for genotyping, identification of resistance patterns, molecularepidemiology analysis, and assembling of complete genomes of new NTM species.

Quan et al. tested the efficacy of WGS for NTM classification compared to conventional available line probe assays (GenoType CM test, GenoType Mycobacterium MTBC or GenoType Mycobacterium AS test). Their results confirmed the high agreement of the individual methods, of which sequencing showed the highest discriminatory power, including within complex diversity (important especially within M. avium complex and 
M. abscessus complex) and identification of rare species, for example, $M$. ratisbonense or M. tomidae [29]. This is due to the limited number of amplified genes included in the conventional assays in combination with higher homology between mycobacterial species in contrast with other bacterial species [30]. The disadvantage of WGS compared to line probe assay is a slightly longer turnaround time (3-15 days). Similarly, the study by Yoon et al. confirmed $100 \%$ compliance of WGS and classical molecular genetic methods (PCR and direct sequencing) in the diagnostics of M. avium subsp. hominissuis, M. intracellulare, and M. abscessus [21].

In addition, WGS has proven to be a suitable tool to distinguish between relapse and reinfection of NTM caused predominantly by M. ulcerans or M. abscessus [31,32]. WGS also allows the identification of NTM at the clone level, thus allowing the form (relapse/reinfection) of the ongoing disease to be determined [33]. Flohr et al. have applied WGS in diagnostics of factitious disorders caused by NTM that may be misdiagnosed as a recurrent or chronic forms of infection [34]. The need to correctly clarify the form of the disease is highlighted by the high recurrence rate of some NTM infections, which is up to $10-48 \%$ after successful treatment $[35,36]$.

Accurate diagnosis of NTM is crucial in patients with structural or inflammatory lung disease such as CF, non-cystic fibrosis bronchiectasis, or chronic obstructive pulmonary disease, as these emerging pathogens cause an accelerated decline in lung function and do not respond to aggressive antibiotic treatment in up to $50 \%$ of cases [37]. The most important predisposing factors in CF patients include nutritional condition, presence of bronchiectasis, and impaired mucociliary clearance [38]. In addition, the prevalence of NTM in CF patients is almost 10,000-fold higher compared to the rest of the population [39]. The two most common NTM species isolated in CF belonging to M. avium complex (representing $75 \%$ of NTM infections in CF) and M. abscessus complex (most common M. abscessus subsp. abscessus and M. abscessus subsp. massiliense) with prevalence ranges from 3 to $23 \%$ in CF centers worldwide [40]. The WGS of M. abscessus ATCC19977 showed that this species encoded virulence factors typical of both mycobacterial pathogens and common $\mathrm{CF}$ pathogens (Pseudomonas aeruginosa and Burkholderia cepacia) [41]. Trovato et al. confirmed that WGS can more effectively discriminate $M$. abscessus subspecies in patients with CF in comparison with a variable number of tandem repeat (VNTR) methods [42]. Similar results were shown in a recent study by Redondo et al. in which they successfully diagnosed individual subspecies of M. abscessus in CF- and non-CF patients [43]. Furthermore, M. abscessus complex infections are seen as a contraindication to lung transplant in some CF patients (currently the only cure for CF), due to the high likelihood of re-infection [44]. The risk of disseminated post-transplant infection is potentiated in patients with a positive presence of M. abscessus in sputum before lung transplantation [45,46]. Kavaliunaite et al. confirmed the association between a particular $M$. abscessus sequence type (ST) and the success of heart and lung transplantation in CF patients [47]. These results are particularly important as reported cases are increasing, and in some studies, the rate of NTM infections in lung transplants was up to $8 \%$ and was directly related to an increased risk of death $[48,49]$. In contrast, post-transplant infections caused by $M$. avium complex are less frequent and associated with a higher cure rate [46]. To decrease the risk of mortality, clinicians should consider the pretransplant or posttransplant (colonized by rapidly-growing NTM) chemoprophylaxis in all patients undergoing the lung transplant [50].

The benefit of WGS has also been shown in the management of multiple-NTM infections, the diagnosis of which is necessary for the correct setting of the treatment regimen and outcome expectations, as well as a better understanding of species diversity in various anatomical regions of the lung [51]. A recent WGS study by Shaw et al. analyzing the genomes of $M$. abscessus isolates revealed the multiple subpopulations diversity with different antimicrobial resistance profiles in children with CF. The results of this study are also important for the clinical diagnosis of the disease, as they confirmed a higher diversity of M. abscessus in samples of lungs, chest wounds, and pleural fluid compared to sputum [52]. Sequencing data provided a more detailed subspecies classification in mixed 
cultures compared to conventionally used methods [53,54]. WGS also contributed to the finding of a high interspecies and intraspecies $M$. avium complex diversity in a patient with an ongoing pulmonary form of the disease. These results elevate the clinical potential of WGS, as commercial probes resolve M. avium species only to the complex level [55]. Greninger et al. also used WGS technology to diagnose polymicrobial infection in brain abscess caused by rare, rapidly growing M. immunogenum and M. llatzerense [56].

For diagnostic purposes, better treatment results, and expanding our knowledge of mycobacterial diseases, it is necessary to identify and classify new species/subspecies of NTM $[28,57,58]$. Describing the complete genomes of the novel NTM requires a combination of short-read (e.g., Illumina MiSeq, San Diego, CA, USA) and long-read (e.g., MinION, Oxford, UK; PacBio SMRT, Pacific Biosciences, CA, USA) sequencing technologies (Figure 1 and Table 1) [59]. Short-read sequencing is characterized by high accuracy but does not provide information about the complete genome (including $\mathrm{G}+\mathrm{C}$ rich regions, recombination, repetitive PE/PPE regions, deletions, and insertions) [60]. In contrast, long-read sequencing technologies have increased read lengths 100- to 1000-fold with slightly lower accuracy compared to NGS platforms and can span much larger repeat regions than NGS, thus contributing to new genome assembly [61].

Table 1. Comparison of basic sequencing platforms used for complete genome assemblies of new NTM species.

\begin{tabular}{|c|c|c|c|c|}
\hline Sequencing Platform & Read-Length (bp) & Output & Accuracy & Advantage \\
\hline Illumina MiSeq & $25-300$ & $>50 \mathrm{~Gb}$ & $>99 \%$ & $\begin{array}{c}\text { Higher read quality } \\
\text { A lower amount of input } \\
\text { DNA Lower cost per sample }\end{array}$ \\
\hline Ion $\mathrm{PGM}^{\mathrm{TM}}$ & $<400$ & $30-2 \mathrm{~Gb}$ & $<98 \%$ & $\begin{array}{l}\text { Higher read quality } \\
\text { Cost-effective }\end{array}$ \\
\hline MinION & $\begin{array}{l}\text { short to ultra-long } \\
\text { (>4 Mb) reads }\end{array}$ & $300-15 \mathrm{~Gb}$ & $>95 \%$ & $\begin{array}{c}\text { Resolving repetitive regions, } \\
G+C \text { rich regions, and } \\
\text { indels Portable }\end{array}$ \\
\hline $\begin{array}{l}\text { PacBio RS II } \\
\text { (Single } \\
\text { molecule } \\
\text { real-time) }\end{array}$ & $>20,000$ & $1-10 \mathrm{~Gb}$ & $>99.999 \%$ & $\begin{array}{c}\text { Higher read quality } \\
\text { Resolving repetitive regions, } \\
\text { G }+ \text { C rich regions, } \\
\text { and indels }\end{array}$ \\
\hline
\end{tabular}

Matsumoto et al. identified 27 genomes belonging to the novel NTM. In addition, sequencing data obtained using long-read sequencing technology were used in the same study to develop a multi-locus sequence typing database and software to identify mycobacteria. Sensitivity and specificity were highest compared to conventional methods in the characterization of 29 species of NTM [62]. Hendrix et al. combined Illumina and MinION sequencing for whole-genome assembling of $M$. kubicae isolates. Their results have provided detailed information regarding the resistance, virulence and persistence encoded on the chromosome or plasmids of these rare, clinically important pulmonary disease-causing NTM [63]. A recent study showed that MinION sequencing technology can be used to detect mycobacteria directly from clinical samples and diagnose the disease within $20 \mathrm{~min}$, therefore setting the treatment regimen in a clinically relevant time frame [64].

Although NTM resistance is becoming a growing threat, susceptibility testing in clinical laboratories is performed primarily by broth microdilution and macrodilution phenotypic methods which may be difficult to evaluate [65]. Additionally, the treatment for NTM infections usually includes a combination of macrolide antibiotics (such as azithromycin and clarithromycin) with aminoglycosides (for fast-growing NTM) or first-line antituberculosis drugs (for slow-growing NTM). However, for some combinations, clinical breakpoints are not well defined, therefore, the effectiveness of treatment can be greatly reduced $[5,66]$. Generally, many NTM species are naturally resistant to specific drugs, however, improperly adjusted and prolonged treatment regimen leads to the development of acquired resistance in originally drug-sensitive bacterial strains [67]. A key factor 
that plays a role in natural NTM resistance is the low permeability of the mycobacterial cell wall [68]. However, M. abscessus exhibits intrinsic high-level resistance to ethambutol and fluoroquinolones. This resistance is predominantly associated with mutations in the $e m b B$ (encoded resistance to ethambutol) and gyr $A$ (encoded resistance to fluoroquinolones) genes [69]. M. abscessus and M. avium exhibit intrinsic resistance to rifampicin, primarily due to mutations in the $r p o B$ gene and the presence of the MAB_0591 gene [65]. Another important mechanism of intrinsic resistance is the overexpression of efflux pumps, which is responsible for the resistance of $M$. abscessus, $M$. avium, and M. intracellulare to bedachilin and clafazimine [70-72]. Acquired drug resistance in mycobacteria is often mediated by a chromosomal mutation in genes encoding targets [73]. With the utility of WGS, it is possible to describe the underlying mechanisms behind the drug resistance of NTM species and increase the effectiveness of treatment regimens [74]. Wetzstein et al. studied the efficacy of WGS in predicting $M$. abscessus resistance to macrolides and aminoglycosides. The results obtained by WGS were shown to be in full agreement with the Genotype NTM-DR line probe assay and phenotypic drug susceptibility testing [75]. Lipworth et al. used sequencing data obtained from $M$. abscessus species for the identification of new mutations in erm and rrs genes potentially associated with macrolide antibiotic resistance. These mutations are not currently included in traditional genotyping tests (such as GenoType NTM-DR; Hain Lifescience, Nehren, Germany) which may therefore show false-negative results [76]. Similarly, Chen et al. performed WGS on clofazimine-resistant strains of M. abscessus. Their results revealed several high-confidence gene mutations (in MAB_2299c, MAB_1483, and MAB_0540 genes) involved in resistance to this drug, whose use is increasingly preferred due to limited treatment options [77]. In addition, M. abscessus subsp. abscessus possesses the erm gene, while $M$. abscessus subsp. massiliense harbor the nonfunctional variant of this gene that lacks the inducible resistance phenotype, so it is important in clinical practice to distinguish between these two subspecies [62]. In contrast, a recent WGS study involving a global collection of $M$. abscessus complex isolates revealed a $10 \%$ higher frequency of mutations in the $\mathrm{rrl}$ gene encoding macrolide resistance in $M$. massiliense compared to M. abscessus subsp. abscessus [78]. Based on WGS-data, Yoshida et al. developed special DNA-chromatographic and PCR-based diagnostic assays for discriminating macrolideresistant/susceptible subspecies of M. abscessus (M. massiliense, M. abscessus, M. bolletii). The agreement rate with WGS was 99.7\% [79]. Realegano et al. developed a novel clinical whole genome sequencing assay to determine the resistance of $M$. abscessus to clarithromycin and amikacin. The accuracy of resistance prediction compared to phenotypic results was 100\% for both drugs [80].

However, the increased incidence of resistant strains is leading to the development of new treatment strategies such as treatment with lytic phages. Dedrick et al. used WGS for a better understanding of phage resistance mechanisms of M. abscessus [81].

\section{WGS Perspectives in Tracing the Transmission of Nosocomial NTM Infection}

Nosocomial NTM infections have been defined as infections directly associated with a hospital stay, or their symptoms may appear immediately after discharge [82]. The first cases of nosocomial NTM infections caused by $M$. fortuitum have been recorded since the beginning of the 20th century [83]. Nowadays, NTMs are classified as welladopted nosocomial pathogens with a wide range of clinical manifestations and hospital sources of infection [26]. Their adaptation to the hospital environment results from their resistance to disinfectants and sterilants, low nutrient requirements, and ability to form a biofilm [2]. These nosocomial infections are usually extrapulmonary: bloodstream infections, postoperative wound infections, implant-associated infections, spinal infections, etc. [84].

Genotyping of individual NTM strains is crucial for tracing the nosocomial outbreaks and epidemiological investigation. Previously preferred typing methods, including biotyping, serotyping, and antibiograms, are no longer performed in reference laboratories due to their insufficient discriminatory power. Current genotyping techniques based on $16 \mathrm{~S}$ 
rRNA sequencing, pulsed-field gel electrophoresis, VNTR, and spoligotyping or plasmid typing, are relatively easy to perform in a short time frame and require only equipment available in most laboratories [85]. However, these techniques show some limitations in recognizing similarities and differences between close phylogenetically similar strains, which are reflected in the misalignment of these strains within clusters and by the inability to identify their common ancestor $[86,87]$. Recent studies confirmed that WGS exhibits higher discriminatory power and a wide range of uses in molecular-epidemiology analysis than current genotyping techniques (Figure 2) $[88,89]$. The results of Harris et al. confirmed higher resolution of WGS in comparison with VNTR profiling in distinguishing NTM subspecies into individual clades [90]. The WGS phylogenomic analysis is usually based on the identification of a massive number of different single nucleotide variants between isolates to cluster and compare genomes, infer relatedness and identify the source of infection. A factor complicating the diagnosis of the disease as well as the tracing for the source of the infection is the long incubation period, which can last several months or years [91].

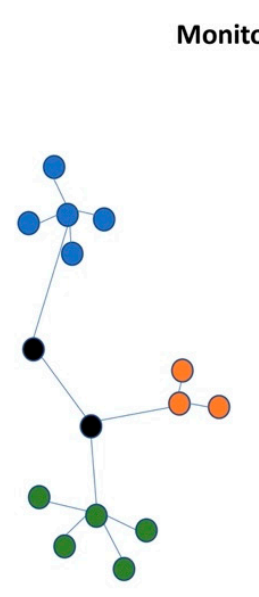

Characterization of local outbreaks and reduction of the spread of NTM at the national level

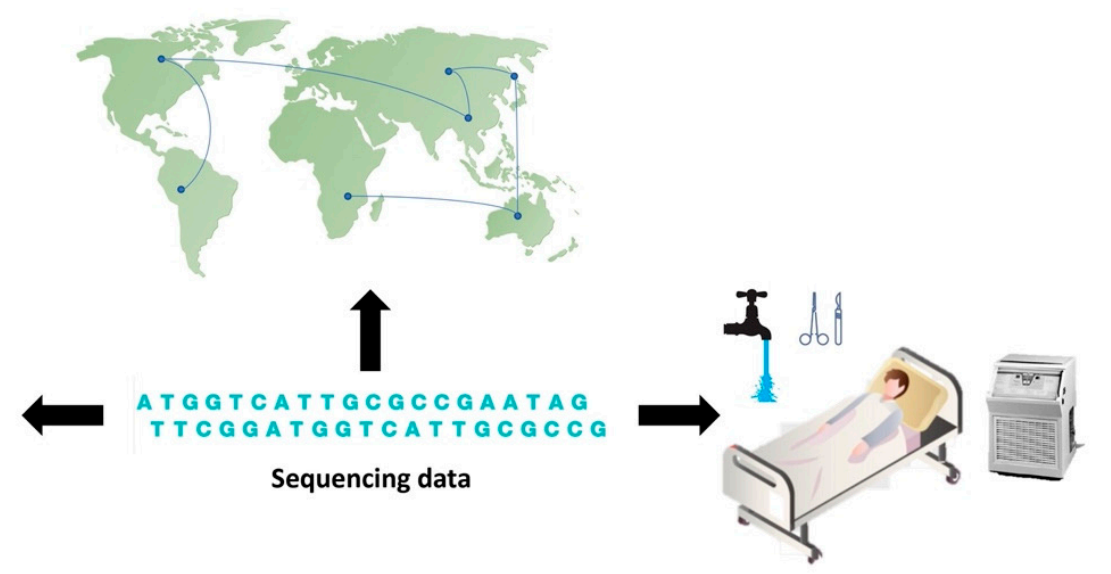

Identification of the source of nosocomial infection

Figure 2. The contribution of WGS in the molecular epidemiology of NTM infections. Sequencing data can be used to describe the global spread and dynamics of NTM infections, to characterize local outbreaks, and also to identify sources of infection in hospital settings.

In the past, it was believed that NTM were transmitted to humans only after exposure to the environment, including soil particles or water droplets containing mycobacteria. The ability of NTM to survive and proliferate in this environment is provided by a lipid-rich and triple-layered outer membrane that protects the cells against acids, high temperatures, and ultraviolet light [2]. However, WGS served to shift this paradigm by allowing the characterization of patient-to-patient transmission events and contributing to an increase in reports of outbreaks of nosocomial NTM infection. In 2012, Aitken et al. reported person-to-person transmission of $M$. abscessus subsp. massiliense among the patients with $\mathrm{CF}$ for the first time [92]. Further studies followed documenting healthcare-associated cross-transmission of $M$. abscessus between CF patients, including pediatric patients in national CF centers (with less than 7 SNP difference between isolates) [25,93-96]. In many of these studies, the specific lineage was isolated only from patients and not from environmental sources. Moreover, Bryant et al. performed a WGS-based study of a collection of M. abscessus isolates obtained from worldwide (Europe, Australia, the Republic of Ireland, and the United States) community of CF patients (1080 isolates from 510 CF patients). The results confirmed the global circulation of three dominant, genetically similar, multi-drug resistant $M$. abscessus clones (74\% isolates were clustered) that are transmitted within CF clinics $[97,98]$. These clones are associated with poorer clinical outcomes and showed increased intracellular survival, pathogenicity, and virulence in macrophage and mouse models [99]. Interestingly, the study of Lipworth et al. showed that most genetically related 
M. abscessus clones isolated from CF patients had no identifiable relevant epidemiological traceback [100]. In addition, Bronson et al. performed a comparative genomic analysis of 1279 M. abscessus complex genomes from CF and non-CF patients. The results of the study identified small pairwise SNP distances and similar phylogenetic patterns between isolates from patients with $\mathrm{CF}$ and without $\mathrm{CF}$, suggesting that these cases originate from a recent common ancestor [77]. However, how these clones are widespread worldwide, either by asymptomatic transmission or by the environment, has not yet been confirmed. Nevertheless, the prevention and control guidelines recommend isolating infected patients to prevent further transmission of M. abscessus within healthcare facilities [101].

In addition to $M$. abscessus, the transmission of M. avium complex (predominantly M. chimaera) was also studied. A recent study defining the genetic relationship of M. avium complex isolates between patients and between patients and their environment confirmed the minimal likelihood of patient-to-patient transmission and identified the hospital water distribution system as the main reservoir of NTM [21]. Moreover, WGS has contributed to the characterization of the global outbreak of nosocomial infections caused by $M$. chimaera in patients who underwent cardiac surgery. These infections are usually presented as prosthetic valve endocarditis, disseminated infections, or infections of vascular grafts [102]. The first outbreak investigation began in 2013 at the University Hospital Zurich in patients with confirmed presence of $M$. chimaera after cardiac surgery [103]. WGS epidemiological analysis in other studies demonstrated that aerosols from the water tanks in the heatercooler units contaminated with $M$. chimaera can be airborne disseminated to patients and the surrounding environment $[87,104-108]$. In this context, Götting et al. found the genetically related $M$. chimaera contaminated the air of the heater-cooler units as well as medical instruments in the operating room [109]. Most of the reported nosocomial outbreaks included patients who were exposed to heater-cooler units from the same manufacturer during the open-heart surgery (LivaNova, London, United Kingdom). A subsequent study confirmed the culture positivity of $M$. chimaera in water samples on the manufacturer's site and thus confirmed the source of infection [107]. Despite the aggressive therapy with the combination of at least 3 antibiotics (usually including the ethambutol, rifamycin, and macrolide) and surgical removal of any involved devices, $50 \%$ of the patients died from complications associated with $M$. chimaera infection. This is due to the ability of $M$. chimaera to replicate in the tissues and disseminate to other organs even with previous long antibiotic therapy [110]. The Centers for Disease Control and Prevention (CDC, Atlanta, GA, USA) has also recently released guidelines for the management and diagnostics of heater-cooler unit-associated NTM infections, in which WGS plays a crucial role [111]. The available data also suggest that the risk of $M$. chimaera infection in patients after cardiac surgery is almost identical to the level of risk of infection in HIV-positive patients [112]. Moreover, clinical symptoms and laboratory findings are often nonspecific, therefore, every patient with a diagnosis of sarcoidosis or culture-negative endocarditis after exposure to a heatercooler unit should be considered as M. chimaera positive [113]. Surgical site infection by M. chimaera may also occur, predominantly in patients after plastic surgery. WGS showed the genetic relatedness of isolates from patients and the samples of tap water at the surgical clinic, therefore exposure of the wound to any non-sterile water should be totally forbidden before complete wound healing [114]. Insufficient sterilization of surgical instruments and water has been suggested as a source of M. chimaera in many other studies, highlighting the utility of WGS in clinical practice $[115,116]$.

Labuda et al. used the WGS approach for characterization of a new species of rapidly growing NTM (Mycobacterium FVL 201832) and identification of saline flushes as a source of nosocomial bloodstream infections in oncology patients. These results contributed to the consideration of new state regulations to monitor and reduce the spread of NTM in oncology clinics [117]. Adherence to these regulations is essential, as recent studies have confirmed that $M$. avium complex infection increases tumor-genes inflammatory responses which could lead to the development of lung and breast cancer and other complications in oncological patients [118]. Similarly, a study by Inkster et al. revealed hospital water 
supply contaminated with $M$. chelonae as a potential source of infection in hemato-oncology patients [119]. The genetic diversity of unique species of $M$. shigaense (belonging to M. simiae complex) causing cutaneous infections have been studied using WGS technology [120].

\section{Conclusions}

NTM infections are associated with a substantially impaired quality of life, increased morbidity, and mortality, and high treatment costs, therefore, it is essential to use sufficiently sensitive diagnostic methods such as WGS. Even though the cost of WGS samples decreases every year, the implementation of this method in clinical diagnostic laboratories requires a higher initial capital and well-trained personal therefore is not available in the mycobacteriology laboratory in resource-limited countries. It is also time-consuming compared to traditionally used tools, as culture cultivation must be performed prior to DNA isolation. Therefore, more research is focused on WGS directly from clinical material. Another limitation in the implementation of WGS into routine practice is also caused by the bioinformatics processing of sequencing data. Nowadays, it requires demanding software and programming skills. However, technological advances in the coming years will lead to the development of easy-to-use online webtools such as TB-Profiler (https:/ / tbdr.lshtm.ac.uk/, accessed on 22 October 2021) or PhyResSE (https: / / bioinf.fz-borstel.de/mchips / phyresse/, accessed on 22 October 2021), which are used to diagnose and determine the complete resistance profile of $M$. tuberculosis.

In contrast, the WGS-data are more comprehensive as these allow the precise identification of novel NTM species from human samples, prediction of genes for virulence, intracellular existence, disease, defense, and toxic compounds of NTM, thus emphasizing other applications of this method (Table 2) [58,121,122]. Moreover, extended datasets of clinical phenotypes and bacterial DNA sequences could resolve ambiguities in the pathogenesis of NTM. We also assume that in the future, the results of WGS will lead to wider use of personalized medicine and thus increase the effectiveness of treatment regimens.

Table 2. Current and potential benefits of WGS in the management of NTM infections.

Accurate diagnostics of NTM infection within a clinically relevant time frame
Unrestricted classification of NTM subspecies compared to other genotyping methods
Characterization of the resistance profile and identification of novel gene mutation
encoding resistance
Setting the appropriate combination of antibiotics and increasing the effectiveness of the
treatment regimen
Monitoring of transmission dynamics and clustering of NTM in hospital settings to prevent
nosocomial infections
Description of new genes affecting the pathogenesis of NTM infections
Development of new drugs

In conclusion, the more NTM genomes are sequenced, the more they will contribute to the global tracing of NTM infections and the description of important genetic determinants, thus the development of novel diagnostic tools and new therapeutic targets.

Author Contributions: Writing—original draft preparation, M.D., I.P.; writing—review and editing, I.S., J.M.; supervision, J.M.; funding acquisition, J.M. All authors have read and agreed to the published version of the manuscript.

Funding: This research was funded by grant APVV-18-0084 and VEGA-1/0093/22.

Conflicts of Interest: The authors declare no conflict of interest. 


\section{References}

1. Fedrizzi, T.; Meehan, C.; Grottola, A.; Giacobazzi, E.; Serpini, G.F.; Tagliazucchi, S.; Fabio, A.; Bettua, C.; Bertorelli, R.; De Sanctis, V.; et al. Genomic characterization of Nontuberculous Mycobacteria. Sci. Rep. 2017, 7, srep45258. [CrossRef]

2. Falkinham, I.J. Surrounded by mycobacteria: Nontuberculous mycobacteria in the human environment. J. Appl. Microbiol. 2009, 107, 356-367. [CrossRef]

3. Falkinham, J.O. Nontuberculous Mycobacteria from Household Plumbing of Patients with Nontuberculous Mycobacteria Disease. Emerg. Infect. Dis. 2011, 17, 419-424. [CrossRef]

4. Esteban, J.; García-Pedrazuela, M.; Muñoz-Egea, M.C.; Alcaide, F. Current treatment of nontuberculous mycobacteriosis: An update. Expert Opin. Pharm. 2012, 13, 967-986. [CrossRef]

5. Saxena, S.; Spaink, H.P.; Forn-Cuní, G. Drug Resistance in Nontuberculous Mycobacteria: Mechanisms and Models. Biology 2021, 10, 96. [CrossRef]

6. Katale, B.Z.; Mbugi, E.V.; Karimuribo, E.D.; Keyyu, J.D.; Kendall, S.; Kibiki, G.S.; Godfrey-Faussett, P.; Michel, A.L.; Kazwala, R.R.; Van Helden, P.; et al. Prevalence and risk factors for infection of bovine tuberculosis in indigenous cattle in the Serengeti ecosystem, Tanzania. BMC Vet. Res. 2013, 9, 1-11. [CrossRef]

7. Lattos, A.; Giantsis, I.A.; Karagiannis, D.; Theodorou, J.A.; Michaelidis, B. Gut Symbiotic Microbial Communities in the IUCN Critically Endangered Pinna nobilis Suffering from Mass Mortalities, Revealed by 16S rRNA Amplicon NGS. Pathogens 2020, 9, 1002. [CrossRef]

8. Lattos, A.; Giantsis, I.A.; Karagiannis, D.; Michaelidis, B. First detection of the invasive Haplosporidian and Mycobacteria parasites hosting the endangered bivalve Pinna nobilis in Thermaikos Gulf, North Greece. Mar. Environ. Res. 2020, 155, 104889. [CrossRef]

9. Prevots, D.R.; Marras, T.K. Epidemiology of Human Pulmonary Infection with Nontuberculous Mycobacteria: A review. Clin. Chest Med. 2015, 36, 13-34. [CrossRef]

10. Degiacomi, G.; Chiarelli, L.; Recchia, D.; Petricci, E.; Gianibbi, B.; Fiscarelli, E.; Fattorini, L.; Manetti, F.; Pasca, M. The Antimalarial Mefloquine Shows Activity against Mycobacterium abscessus, Inhibiting Mycolic Acid Metabolism. Int. J. Mol. Sci. 2021, $22,8533$. [CrossRef]

11. Larsson, L.-O.; Polverino, E.; Hoefsloot, W.; Codecasa, L.R.; Diel, R.; Jenkins, S.G.; Loebinger, M.R. Pulmonary disease by non-tuberculous mycobacteria-Clinical management, unmet needs and future perspectives. Expert Rev. Respir. Med. 2017, 11, 977-989. [CrossRef] [PubMed]

12. Szymanski, E.P.; Leung, J.M.; Fowler, C.J.; Haney, C.; Hsu, A.P.; Chen, F.; Duggal, P.; Oler, A.J.; McCormack, R.; Podack, E.; et al. Pulmonary Nontuberculous Mycobacterial Infection. A Multisystem, Multigenic Disease. Am. J. Respir. Crit. Care Med. 2015, 192, 618-628. [CrossRef]

13. Mirsaeidi, M.; Farshidpour, M.; Allen, M.B.; Ebrahimi, G.; Falkinham, J.O. Highlight on Advances in Nontuberculous Mycobacterial Disease in North America. BioMed Res. Int. 2014, 2014, 1-10. [CrossRef] [PubMed]

14. Ryu, Y.J.; Koh, W.-J.; Daley, C.L. Diagnosis and Treatment of Nontuberculous Mycobacterial Lung Disease: Clinicians' Perspectives. Tuberc. Respir. Dis. 2016, 79, 74-84. [CrossRef]

15. Porvaznik, I.; Solovič, I.; Mokrý, J. Non-Tuberculous Mycobacteria: Classification, Diagnostics, and Therapy. Adv. Exp. Med. Biol. 2017, 944, 19-25. [CrossRef]

16. Cowman, S.A.; Loebinger, M.R. Diagnosis of Nontuberculous Mycobacteria Lung Disease. Semin. Respir. Crit. Care Med. 2018, 39, 343-350. [CrossRef]

17. Johnson, M.M.; Odell, J.A. Nontuberculous mycobacterial pulmonary infections. J. Thorac. Dis. 2014, 6, 210-220. [CrossRef]

18. Chopra, K.; Sidiq, Z.; Hanif, M.; Dwivedi, K.K. Advances in the diagnosis of tuberculosis- Journey from smear microscopy to whole genome sequencing. Indian J. Tuberc. 2020, 67, S61-S68. [CrossRef]

19. Somoskovi, A.; Salfinger, M. Nontuberculous Mycobacteria in Respiratory Infections: Advances in diagnosis and identification. Clin. Lab. Med. 2014, 34, 271-295. [CrossRef]

20. Dohál, M.; Porvazník, I.; Pršo, K.; Rasmussen, E.M.; Solovič, I.; Mokrý, J. Whole-genome sequencing and Mycobacterium tuberculosis: Challenges in sample preparation and sequencing data analysis. Tuberculosis 2020, 123, 101946. [CrossRef]

21. Yoon, J.-K.; Kim, T.S.; Kim, J.-I.; Yim, J.-J. Whole genome sequencing of Nontuberculous Mycobacterium (NTM) isolates from sputum specimens of co-habiting patients with NTM pulmonary disease and NTM isolates from their environment. BMC Genom. 2020, 21, 1-7. [CrossRef]

22. Hirabayashi, R.; Nakagawa, A.; Takegawa, H.; Tomii, K. A case of pleural effusion caused by Mycobacterium fortuitum and Mycobacterium mageritense coinfection. BMC Infect. Dis. 2019, 19, 1-3. [CrossRef] [PubMed]

23. Walker, T.M.; Merker, M.; Knoblauch, A.; Helbling, P.; Schoch, O.D.; van der Werf, M.J.; Kranzer, K.; Fiebig, L.; Kröger, S.; Haas, W.; et al. A cluster of multidrug-resistant Mycobacterium tuberculosis among patients arriving in Europe from the Horn of Africa: A molecular epidemiological study. Lancet Infect. Dis. 2018, 18, 431-440. [CrossRef]

24. Genestet, C.; Hodille, E.; Berland, J.-L.; Ginevra, C.; Bryant, J.E.; Ader, F.; Lina, G.; Dumitrescu, O. Whole-genome sequencing in drug susceptibility testing of Mycobacterium tuberculosis in routine practice in Lyon, France. Int. J. Antimicrob. Agents 2020, 55, 105912. [CrossRef]

25. Mehta, M.; Marras, T.K. Impaired health-related quality of life in pulmonary nontuberculous mycobacterial disease. Respir. Med. 2011, 105, 1718-1725. [CrossRef] 
26. Nishiuchi, Y.; Iwamoto, T.; Maruyama, F. Infection Sources of a Common Non-tuberculous Mycobacterial Pathogen, Mycobacterium avium Complex. Front. Med. 2017, 4, 27. [CrossRef]

27. Advani, J.; Verma, R.; Chatterjee, O.; Pachouri, P.K.; Upadhyay, P.; Singh, R.; Yadav, J.; Naaz, F.; Ravikumar, R.; Buggi, S.; et al. Whole Genome Sequencing of Mycobacterium tuberculosis Clinical Isolates from India Reveals Genetic Heterogeneity and Region-Specific Variations That Might Affect Drug Susceptibility. Front. Microbiol. 2019, 10, 309. [CrossRef]

28. Tortoli, E. Microbiological Features and Clinical Relevance of New Species of the Genus Mycobacterium. Clin. Microbiol. Rev. 2014, 27, 727-752. [CrossRef]

29. Quan, T.P.; Bawa, Z.; Foster, D.; Walker, T.; Elías, C.D.O.; Rathod, P.; Iqbal, Z.; Bradley, P.; Mowbray, J.; Walker, A.S.; et al. Evaluation of Whole-Genome Sequencing for Mycobacterial Species Identification and Drug Susceptibility Testing in a Clinical Setting: A Large-Scale Prospective Assessment of Performance against Line Probe Assays and Phenotyping. J. Clin. Microbiol. 2018, 56, e01480-17. [CrossRef]

30. Hoshino, Y.; Suzuki, K. Differential diagnostic assays for discriminating mycobacteria, especially for nontuberculous mycobacteria: What does the future hold? Future Microbiol. 2015, 10, 205-216. [CrossRef]

31. Morimoto, K.; Aono, A.; Murase, Y.; Sekizuka, T.; Kurashima, A.; Takaki, A.; Sasaki, Y.; Igarashi, Y.; Chikamatsu, K.; Goto, H.; et al. Prevention of aerosol isolation of nontuberculous Mycobacterium from the patient's bathroom. ERJ Open Res. 2018, 4, 00150-02017. [CrossRef] [PubMed]

32. Bryant, J.; Grogono, D.; Greaves, D.; Foweraker, J.; Roddick, I.; Inns, T.; Reacher, M.; Haworth, C.S.; Curran, M.D.; Harris, S.; et al. Whole-genome sequencing to identify transmission of Mycobacterium abscessus between patients with cystic fibrosis: A retrospective cohort study. Lancet 2013, 381, 1551-1560. [CrossRef]

33. Fukushima, K.; Kitada, S.; Matsumoto, Y.; Komukai, S.; Kuge, T.; Kawasaki, T.; Matsuki, T.; Motooka, D.; Tsujino, K.; Miki, M.; et al. Serum GPL core antibody levels are associated with disease activity and treatment outcomes in Mycobacterium avium complex lung disease following first line antibiotic treatment. Respir. Med. 2021, 187, 106585. [CrossRef] [PubMed]

34. Flohr, S.; Ramette, A.; Agyeman, P.K.A.; Duppenthaler, A.; Scherer, C.; Keller, P.M.; Aebi, C. Recurrent Mycobacterium chelonae Skin Infection Unmasked as Factitious Disorder Using Bacterial Whole Genome Sequence Analysis. Open Forum Infect. Dis. 2020, 7, ofaa506. [CrossRef]

35. Lee, B.Y.; Kim, S.; Hong, Y.; Lee, S.-D.; Kim, W.S.; Kim, D.S.; Shim, T.S.; Jo, K.-W. Risk Factors for Recurrence after Successful Treatment of Mycobacterium avium Complex Lung Disease. Antimicrob. Agents Chemother. 2015, 59, 2972-2977. [CrossRef] [PubMed]

36. Boyle, D.P.; Zembower, T.R.; Qi, C. Relapse versus Reinfection of Mycobacterium avium Complex Pulmonary Disease. Patient Characteristics and Macrolide Susceptibility. Ann. Am. Thorac. Soc. 2016, 13, 1956-1961. [CrossRef] [PubMed]

37. Floto, R.A.; Olivier, K.N.; Saiman, L.; Daley, C.L.; Herrmann, J.-L.; Nick, J.A.; Noone, P.G.; Bilton, D.; Corris, P.; Gibson, R.L.; et al. US Cystic Fibrosis Foundation and European Cystic Fibrosis Society consensus recommendations for the management of non-tuberculous mycobacteria in individuals with cystic fibrosis. Thorax 2015, 71, i1-i22. [CrossRef] [PubMed]

38. Kim, R.D.; Greenberg, D.E.; Ehrmantraut, M.E.; Guide, S.V.; Ding, L.; Shea, Y.; Brown, M.R.; Chernick, M.; Steagall, W.K.; Glasgow, C.G.; et al. Pulmonary Nontuberculous Mycobacterial Disease: Prospective study of a distinct preexisting syndrome. Am. J. Respir. Crit. Care Med. 2008, 178, 1066-1074. [CrossRef]

39. Lake, M.A.; Ambrose, L.R.; Lipman, M.C.I.; Lowe, D.M. “Why me, why now?” Using clinical immunology and epidemiology to explain who gets nontuberculous mycobacterial infection. BMC Med. 2016, 14, 1-13. [CrossRef] [PubMed]

40. Aiello, T.B.; Levy, C.; Zaccariotto, T.R.; Paschoal, I.A.; Pereira, M.C.; Da Silva, M.T.N.; Ribeiro, J.D.; Ribeiro, A.F.; Toro, A.D.C.; Mauch, R.M. Prevalence and clinical outcomes of nontuberculous mycobacteria in a Brazilian cystic fibrosis reference center. Pathog. Dis. 2018, 76. [CrossRef]

41. Neulat-Ripoll, F.; Pasek, S.; Schenowitz, C.; Dossat, C.; Barbe, V.; Rottman, M.; Macheras, E.; Heym, B.; Herrmann, J.-L.; Daffé, M.; et al. Non Mycobacterial Virulence Genes in the Genome of the Emerging Pathogen Mycobacterium abscessus. PLoS ONE 2009, 4, e5660. [CrossRef]

42. Tortoli, E.; Trovato, A.; Baldan, R.; Costa, D.; Simonetti, T.M.; Cirillo, D.M. Molecular typing of Mycobacterium abscessus isolated from cystic fibrosis patients. Int. J. Mycobacteriol. 2017, 6, 138-141. [CrossRef] [PubMed]

43. Redondo, N.; Mok, S.; Montgomery, L.; Flanagan, P.; McNamara, E.; Smyth, E.G.; O'Sullivan, N.; Schaffer, K.; Rogers, T.R.; Fitzgibbon, M.M. Genomic Analysis of Mycobacterium abscessus Complex Isolates Collected in Ireland between 2006 and $2017 . J$. Clin. Microbiol. 2020, 58, e00295-20. [CrossRef] [PubMed]

44. Gilljam, M.; Scherstén, H.; Silverborn, M.; Jönsson, B.; Hollsing, A.E. Lung transplantation in patients with cystic fibrosis and Mycobacterium abscessus infection. J. Cyst. Fibros. 2010, 9, 272-276. [CrossRef]

45. Lobo, L.J.; Chang, L.C.; Esther, C.R.; Gilligan, P.H.; Tulu, Z.; Noone, P.G. Lung transplant outcomes in cystic fibrosis patients with pre-operative Mycobacterium abscessus respiratory infections. Clin. Transplant. 2013, 27, 523-529. [CrossRef] [PubMed]

46. Qvist, T.; Pressler, T.; Thomsen, V.; Skov, M.; Iversen, M.; Katzenstein, T. Nontuberculous Mycobacterial Disease Is Not a Contraindication to Lung Transplantation in Patients with Cystic Fibrosis: A Retrospective Analysis in a Danish Patient Population. Transplant. Proc. 2013, 45, 342-345. [CrossRef]

47. Kavaliunaite, E.; Harris, K.A.; Aurora, P.; Dixon, G.; Shingadia, D.; Muthialu, N.; Spencer, H. Outcome according to subspecies following lung transplantation in cystic fibrosis pediatric patients infected with Mycobacterium abscessus. Transpl. Infect. Dis. 2020, 22, e13274. [CrossRef] [PubMed] 
48. Keating, M.R.; Daly, J.S. Nontuberculous mycobacterial infections in solid organ transplantation. Am. J. Transplant. 2013, 13, 77-82. [CrossRef] [PubMed]

49. Friedman, D.Z.P.; Cervera, C.; Halloran, K.; Tyrrell, G.; Doucette, K. Non-tuberculous mycobacteria in lung transplant recipients: Prevalence, risk factors, and impact on survival and chronic lung allograft dysfunction. Transpl. Infect. Dis. 2020, 22 , e13229. [CrossRef]

50. Huang, H.C.; Weigt, S.S.; Derhovanessian, A.; Palchevskiy, V.; Ardehali, A.; Saggar, R.; Saggar, R.; Kubak, B.; Gregson, A.; Ross, D.J.; et al. Non-tuberculous Mycobacterium infection after lung transplantation is associated with increased mortality. J. Heart Lung Transplant. 2011, 30, 790-798. [CrossRef] [PubMed]

51. Daniel-Wayman, S.; Abate, G.; Barber, D.L.; Bermudez, L.E.; Coler, R.N.; Cynamon, M.H.; Daley, C.L.; Davidson, R.M.; Dick, T.; Floto, R.A.; et al. Advancing Translational Science for Pulmonary Nontuberculous Mycobacterial Infections. A Road Map for Research. Am. J. Respir. Crit. Care Med. 2019, 199, 947-951. [CrossRef]

52. Shaw, L.P.; Doyle, R.M.; Kavaliunaite, E.; Spencer, H.; Balloux, F.; Dixon, G.; Harris, K. Children with Cystic Fibrosis Are Infected with Multiple Subpopulations of Mycobacterium abscessus With Different Antimicrobial Resistance Profiles. Clin. Infect. Dis. 2019, 69, 1678-1686. [CrossRef] [PubMed]

53. Pfeiffer, W.; Braun, J.D.; Burchell, J.; Witte, C.L.; Rideout, B.A. Whole-genome analysis of mycobacteria from birds at the San Diego Zoo. PLoS ONE 2017, 12, e0173464. [CrossRef]

54. Khieu, V.; Ananta, P.; Kaewprasert, O.; Laohaviroj, M.; Namwat, W.; Faksri, K. Whole-Genome Sequencing Analysis to Identify Infection with Multiple Species of Nontuberculous Mycobacteria. Pathogens 2021, 10, 879. [CrossRef] [PubMed]

55. Operario, D.J.; Pholwat, S.; Koeppel, A.F.; Prorock, A.; Bao, Y.; Sol-Church, K.; Scheurenbrand, M.; Poulter, M.; Turner, S.; Parikh, H.I.; et al. Mycobacterium avium Complex Diversity within Lung Disease, as Revealed by Whole-Genome Sequencing. Am. J. Respir. Crit. Care Med. 2019, 200, 393-396. [CrossRef]

56. Greninger, A.; Langelier, C.; Cunningham, G.; Keh, C.; Melgar, M.; Chiu, C.; Miller, S. Two Rapidly Growing Mycobacterial Species Isolated from a Brain Abscess: First Whole-Genome Sequences of Mycobacterium immunogenum and Mycobacterium llatzerense. J. Clin. Microbiol. 2015, 53, 2374-2377. [CrossRef]

57. Tortoli, E.; Kohl, T.A.; Brown-Elliott, B.A.; Trovato, A.; Leao, S.; Garcia, M.J.; Vasireddy, S.; Turenne, C.Y.; Griffith, D.E.; Philley, J.V.; et al. Emended description of Mycobacterium abscessus, Mycobacterium abscessus subsp. abscessus and Mycobacterium abscessus subsp. bolletii and designation of Mycobacterium abscessus subsp. massiliense comb. nov. Int. J. Syst. Evol. Microbiol. 2016, 66, 4471-4479. [CrossRef]

58. Kuge, T.; Fukushima, K.; Matsumoto, Y.; Abe, Y.; Akiba, E.; Haduki, K.; Saito, H.; Nitta, T.; Kawano, A.; Kawasaki, T.; et al. Pulmonary disease caused by a newly identified mycobacterium: Mycolicibacterium toneyamachuris: A case report. BMC Infect. Dis. 2020, 20, 1-5. [CrossRef]

59. Bouso, J.M.; Planet, P.J. Complete nontuberculous mycobacteria whole genomes using an optimized DNA extraction protocol for long-read sequencing. BMC Genom. 2019, 20, 793. [CrossRef]

60. Bainomugisa, A.; Duarte, T.; Lavu, E.; Pandey, S.; Coulter, C.; Marais, B.J.; Coin, L. A complete high-quality MinION nanopore assembly of an extensively drug-resistant Mycobacterium tuberculosis Beijing lineage strain identifies novel variation in repetitive PE/PPE gene regions. Microb. Genom. 2018, 4, e000188. [CrossRef]

61. Tyson, J.R.; O'Neil, N.; Jain, M.; Olsen, H.E.; Hieter, P.; Snutch, T.P. MinION-based long-read sequencing and assembly extends the Caenorhabditis elegans reference genome. Genome Res. 2018, 28, 266-274. [CrossRef]

62. Matsumoto, Y.; Kinjo, T.; Motooka, D.; Nabeya, D.; Jung, N.; Uechi, K.; Horii, T.; Iida, T.; Fujita, J.; Nakamura, S. Comprehensive subspecies identification of 175 nontuberculous mycobacteria species based on 7547 genomic profiles. Emerg. Microbes Infect. 2019, 8, 1043-1053. [CrossRef] [PubMed]

63. Hendrix, J.; Epperson, L.E.; Durbin, D.; Honda, J.R.; Strong, M. Intraspecies plasmid and genomic variation of Mycobacterium kubicae revealed by the complete genome sequences of two clinical isolates. Microb. Genom. 2021, 7, 000497. [CrossRef]

64. Votintseva, A.A.; Bradley, P.; Pankhurst, L.; Elías, C.D.O.; Loose, M.; Nilgiriwala, K.; Chatterjee, A.; Smith, E.G.; Sanderson, N.; Walker, T.M.; et al. Same-Day Diagnostic and Surveillance Data for Tuberculosis via Whole-Genome Sequencing of Direct Respiratory Samples. J. Clin. Microbiol. 2017, 55, 1285-1298. [CrossRef] [PubMed]

65. Johansen, M.D.; Herrmann, J.-L.; Kremer, L. Non-tuberculous mycobacteria and the rise of Mycobacterium abscessus. Nat. Rev. Microbiol. 2020, 18, 392-407. [CrossRef] [PubMed]

66. Ahmed, I.; Tiberi, S.; Farooqi, J.; Jabeen, K.; Yeboah-Manu, D.; Migliori, G.B.; Hasan, R. Non-tuberculous mycobacterial infections-A neglected and emerging problem. Int. J. Infect. Dis. 2020, 92, S46-S50. [CrossRef]

67. Munita, J.M.; Arias, C.A. Mechanisms of Antibiotic Resistance. Microbiol. Spectrum 2021, 4. [CrossRef]

68. Jarlier, V.; Nikaido, H. Mycobacterial cell wall: Structure and role in natural resistance to antibiotics. FEMS Microbiol. Lett. 1994, 123, 11-18. [CrossRef]

69. Nessar, R.; Cambau, E.; Reyrat, J.M.; Murray, A.; Gicquel, B. Mycobacterium abscessus: A new antibiotic nightmare. J. Antimicrob. Chemother. 2012, 67, 810-818. [CrossRef]

70. Richard, M.; Gutiérrez, A.V.; Viljoen, A.; Rodriguez-Rincon, D.; Roquet-Baneres, F.; Blaise, M.; Everall, I.; Parkhill, J.; Floto, R.A.; Kremer, L. Mutations in the MAB_2299c TetR Regulator Confer Cross-Resistance to Clofazimine and Bedaquiline in Mycobacterium abscessus. Antimicrob. Agents Chemother. 2019, 63, e01316-18. [CrossRef] 
71. Rodrigues, L.; Sampaio, D.; Couto, I.; Machado, D.; Kern, W.V.; Amaral, L.; Viveiros, M. The role of efflux pumps in macrolide resistance in Mycobacterium avium complex. Int. J. Antimicrob. Agents 2009, 34, 529-533. [CrossRef] [PubMed]

72. Alexander, D.C.; Vasireddy, R.; Vasireddy, S.; Philley, J.V.; Brown-Elliott, B.A.; Perry, B.J.; Griffith, D.E.; Benwill, J.L.; Cameron, A.; Wallace, R.J. Emergence of mmpT5 Variants during Bedaquiline Treatment of Mycobacterium intracellulare Lung Disease. J. Clin. Microbiol. 2017, 55, 574-584. [CrossRef]

73. Nasiri, M.J.; Haeili, M.; Ghazi, M.; Goudarzi, H.; Pormohammad, A.; Fooladi, A.A.I.; Feizabadi, M.M. New Insights in to the Intrinsic and Acquired Drug Resistance Mechanisms in Mycobacteria. Front. Microbiol. 2017, 8, 681. [CrossRef]

74. Dymova, M.; Alkhovik, O.; Evdokimova, L.; Cherednichenko, A.; Petrenko, T.; Batyrshina, Y. Whole genome-sequencing of non-tuberculous mycobacteria. Eur. Respir. J. 2016, 48, PA891. [CrossRef]

75. Wetzstein, N.; Kohl, T.A.; Andres, S.; Schultze, T.G.; Geil, A.; Kim, E.; Biciusca, T.; Hügel, C.; Hogardt, M.; Lehn, A.; et al. Comparative analysis of phenotypic and genotypic antibiotic susceptibility patterns in Mycobacterium avium complex. Int. J. Infect. Dis. 2020, 93, 320-328. [CrossRef]

76. Lipworth, S.; Hough, N.; Leach, L.; Morgan, M.; Jeffery, K.; Andersson, M.; Robinson, E.; Smith, E.G.; Crook, D.; Peto, T.; et al. Whole-Genome Sequencing for Predicting Clarithromycin Resistance in Mycobacterium abscessus. Antimicrob. Agents Chemother. 2019, 63, e01204-18. [CrossRef]

77. Chen, Y.; Chen, J.; Zhang, S.; Shi, W.; Zhang, W.; Zhu, M.; Zhang, Y. Novel Mutations Associated with Clofazimine Resistance in Mycobacterium abscessus. Antimicrob. Agents Chemother. 2018, 62, e00544-18. [CrossRef]

78. Bronson, R.A.; Gupta, C.; Manson, A.L.; Nguyen, J.A.; Bahadirli-Talbott, A.; Parrish, N.M.; Earl, A.M.; Cohen, K.A. Global phylogenomic analyses of Mycobacterium abscessus provide context for non cystic fibrosis infections and the evolution of antibiotic resistance. Nat. Commun. 2021, 12,1-10. [CrossRef]

79. Yoshida, M.; Sano, S.; Chien, J.-Y.; Fukano, H.; Suzuki, M.; Asakura, T.; Morimoto, K.; Murase, Y.; Miyamoto, S.; Kurashima, A.; et al. A novel DNA chromatography method to discriminate Mycobacterium abscessus subspecies and macrolide susceptibility. EBioMedicine 2021, 64, 103187. [CrossRef]

80. Realegeno, S.; Mirasol, R.; Garner, O.B.; Yang, S. Clinical Whole Genome Sequencing for Clarithromycin and Amikacin Resistance Prediction and Subspecies Identification of Mycobacterium abscessus. J. Mol. Diagn. 2021. [CrossRef]

81. Dedrick, R.M.; Smith, B.E.; Garlena, R.A.; Russell, D.A.; Aull, H.G.; Mahalingam, V.; Divens, A.M.; Guerrero-Bustamante, C.A.; Zack, K.M.; Abad, L.; et al. Mycobacterium abscessus Strain Morphotype Determines Phage Susceptibility, the Repertoire of Therapeutically Useful Phages, and Phage Resistance. mBio 2021, 12, e03431-20. [CrossRef]

82. Phillips, M.; Von Reyn, C.F. Nosocomial Infections Due to Nontuberculous Mycobacteria. Clin. Infect. Dis. 2001, 33, 1363-1374. [CrossRef]

83. Wallace, R.J.; Brown, B.A.; Griffith, D.E. Nosocomial outbreaks/pseudo outbreaks caused by nontuberculous mycobacteria. Annu. Rev. Microbiol. 1998, 52, 453-490. [CrossRef]

84. Shakoor, S.; Owais, M.; Hasan, R.; Irfan, S. Nosocomial and Healthcare-Associated NTM Infections and Their Control. In Nontuberculous Mycobacteria (NTM): Microbiological, Clinical and Geographical Distribution; Elsevier: Amsterdam, The Netherlands, 2019; pp. 177-190. ISBN 9780128146934.

85. Jamieson, F.B.; Teatero, S.; Guthrie, J.L.; Neemuchwala, A.; Fittipaldi, N.; Mehaffy, C. Whole-Genome Sequencing of the Mycobacterium tuberculosis Manila Sublineage Results in Less Clustering and Better Resolution than Mycobacterial Interspersed Repetitive-Unit-Variable-Number Tandem-Repeat (MIRU-VNTR) Typing and Spoligotyping. J. Clin. Microbiol. 2014, 52, 3795-3798. [CrossRef]

86. Trewby, H.; Wright, D.; Breadon, E.L.; Lycett, S.J.; Mallon, T.R.; McCormick, C.; Johnson, P.; Orton, R.J.; Allen, A.R.; Galbraith, J.; et al. Use of bacterial whole-genome sequencing to investigate local persistence and spread in bovine tuberculosis. Epidemics 2016, 14, 26-35. [CrossRef]

87. Price-Carter, M.; Brauning, R.; De Lisle, G.W.; Livingstone, P.; Neill, M.; Sinclair, J.; Paterson, B.; Atkinson, G.; Knowles, G.; Crews, K.; et al. Whole Genome Sequencing for Determining the Source of Mycobacterium bovis Infections in Livestock Herds and Wildlife in New Zealand. Front. Vet. Sci. 2018, 5, 272. [CrossRef] [PubMed]

88. Black, A.T.; Hamblion, E.L.; Buttivant, H.; Anderson, S.R.; Stone, M.; Casali, N.; Drobniewski, F.; Nwoguh, F.; Marshall, B.G.; Booth, L. Tracking and responding to an outbreak of tuberculosis using MIRU-VNTR genotyping and whole genome sequencing as epidemiological tools. J. Public Health 2018, 40, e66-e73. [CrossRef]

89. Ahlstrom, C.; Barkema, H.W.; Stevenson, K.; Zadoks, R.N.; Biek, R.; Kao, R.; Trewby, H.; Haupstein, D.; Kelton, D.F.; Fecteau, G.; et al. Limitations of variable number of tandem repeat typing identified through whole genome sequencing of Mycobacterium avium subsp. paratuberculosis on a national and herd level. BMC Genom. 2015, 16, 161. [CrossRef]

90. Harris, K.A.; Underwood, A.; Kenna, D.T.D.; Brooks, A.; Kavaliunaite, E.; Kapatai, G.; Tewolde, R.; Aurora, P.; Dixon, G. Wholegenome sequencing and epidemiological analysis do not provide evidence for cross-transmission of Mycobacterium abscessus in a cohort of pediatric cystic fibrosis patients. Clin. Infect. Dis. 2015, 60, 1007-1016. [CrossRef]

91. Ratnatunga, C.; Lutzky, V.P.; Kupz, A.; Doolan, D.L.; Reid, D.W.; Field, M.; Bell, S.; Thomson, R.M.; Miles, J.J. The Rise of Non-Tuberculosis Mycobacterial Lung Disease. Front. Immunol. 2020, 11, 303. [CrossRef]

92. Aitken, M.L.; Limaye, A.; Pottinger, P.; Whimbey, E.; Goss, C.; Tonelli, M.R.; Cangelosi, G.A.; Dirac, M.A.; Olivier, K.N.; BrownElliott, B.A.; et al. Respiratory Outbreak of Mycobacterium abscessus Subspecies massiliensein a Lung Transplant and Cystic Fibrosis Center. Am. J. Respir. Crit. Care Med. 2012, 185, 231-232. [CrossRef] 
93. Tortoli, E.; Kohl, T.A.; Trovato, A.; Baldan, R.; Campana, S.; Cariani, L.; Colombo, C.; Costa, D.; Cristadoro, S.; Di Serio, M.C.; et al. Mycobacterium abscessus in patients with cystic fibrosis: Low impact of inter-human transmission in Italy. Eur. Respir. J. 2017, 50, 1602525. [CrossRef] [PubMed]

94. Hasan, N.A.; Davidson, R.M.; Epperson, L.E.; Kammlade, S.M.; Rodger, R.R.; Levin, A.R.; Sherwood, A.; Sagel, S.D.; Martiniano, S.L.; Daley, C.L.; et al. Population genomics of nontuberculous mycobacteria recovered from United States cystic fibrosis patients. bioRxiv 2019, 663559. [CrossRef]

95. Yan, J.; Kevat, A.; Martinez, E.; Teese, N.; Johnson, K.; Ranganathan, S.; Harrison, J.; Massie, J.; Daley, A. Investigating transmission of Mycobacterium abscessus amongst children in an Australian cystic fibrosis centre. J. Cyst. Fibros. 2020, 19, 219-224. [CrossRef]

96. Davidson, R.M.; Benoit, J.B.; Kammlade, S.M.; Hasan, N.A.; Epperson, L.E.; Smith, T.; Vasireddy, S.; Brown-Elliott, B.A.; Nick, J.A.; Olivier, K.N.; et al. Genomic characterization of sporadic isolates of the dominant clone of Mycobacterium abscessus subspecies massiliense. Sci. Rep. 2021, 11, 1-10. [CrossRef] [PubMed]

97. Bryant, J.M.; Grogono, D.M.; Rodriguez-Rincon, D.; Everall, I.; Brown, K.P.; Moreno, P.; Verma, D.; Hill, E.; Drijkoningen, J.; Gilligan, P.; et al. Emergence and spread of a human-transmissible multidrug-resistant nontuberculous mycobacterium. Science 2016, 354, 751-757. [CrossRef] [PubMed]

98. Ravnholt, C.; Kolpen, M.; Skov, M.; Moser, C.; Katzenstein, T.L.; Pressler, T.; Høiby, N.; Qvist, T. The importance of early diagnosis of Mycobacterium abscessus complex in patients with cystic fibrosis. APMIS 2018, 126, 885-891. [CrossRef] [PubMed]

99. Davidson, R.M. A Closer Look at the Genomic Variation of Geographically Diverse Mycobacterium abscessus Clones That Cause Human Infection and Disease. Front. Microbiol. 2018, 9, 2988. [CrossRef]

100. Lipworth, S.; Hough, N.; Weston, N.; Muller-Pebody, B.; Phin, N.; Myers, R.; Chapman, S.; Flight, W.; Alexander, E.; Smith, E.G.; et al. Epidemiology of Mycobacterium abscessus in England: An observational study. Lancet Microbe 2021, 2, e498-e507. [CrossRef]

101. Saiman, L.; Siegel, J.D.; Lipuma, J.J.; Brown, R.; Bryson, E.A.; Chambers, M.J.; Downer, V.S.; Fliege, J.; Hazle, L.A.; Jain, M.; et al. Infection Prevention and Control Guideline for Cystic Fibrosis: 2013 Update. Infect. Control Hosp. Epidemiol. 2014, 35, s1-s67. [CrossRef]

102. Haller, S.; Höller, C.; Jacobshagen, A.; Hamouda, O.; Abu Sin, M.; Monnet, D.L.; Plachouras, D.; Eckmanns, T. Contamination during production of heater-cooler units by Mycobacterium chimaera potential cause for invasive cardiovascular infections: Results of an outbreak investigation in Germany, April 2015 to February 2016. Eurosurveillance 2016, 21, 1-6. [CrossRef]

103. Schreiber, P.W.; Kohl, T.A.; Kuster, S.P.; Niemann, S.; Sax, H. The global outbreak of Mycobacterium chimaera infections in cardiac surgery-A systematic review of whole-genome sequencing studies and joint analysis. Clin. Microbiol. Infect. 2021. [CrossRef] [PubMed]

104. van Ingen, J.; Kohl, T.A.; Kranzer, K.; Hasse, B.; Keller, P.M.; Szafrańska, A.K.; Hillemann, D.; Chand, M.; Schreiber, P.W.; Sommerstein, R.; et al. Global outbreak of severe Mycobacterium chimaera disease after cardiac surgery: A molecular epidemiological study. Lancet Infect. Dis. 2017, 17, 1033-1041. [CrossRef]

105. Svensson, E.; Jensen, E.T.; Rasmussen, E.M.; Folkvardsen, D.B.; Norman, A.; Lillebaek, T. Mycobacterium chimaera in Heater-Cooler Units in Denmark Related to Isolates from the United States and United Kingdom. Emerg. Infect. Dis. 2017, 23, 507-509. [CrossRef]

106. Diekema, D.J. Mycobacterium chimaera infections after cardiovascular surgery: Lessons from a global outbreak. Trans. Am. Clin. Climatol. Assoc. 2019, 130, 136-144.

107. Ghodousi, A.; Borroni, E.; Peracchi, M.; Palù, G.; Fallico, L.; Rassu, M.; Manfrin, V.; Mantegani, P.; Monzillo, V.; Manganelli, R.; et al. Genomic analysis of cardiac surgery-associated Mycobacterium chimaera infections in Italy. PLoS ONE 2020, 15, e0239273. [CrossRef]

108. Lecorche, E.; Daniau, C.; La, K.; Mougari, F.; Benmansour, H.; Kumanski, S.; Robert, J.; Fournier, S.; Lebreton, G.; Carbonne, A.; et al. Mycobacterium chimaera Genomics with Regard to Epidemiological and Clinical Investigations Conducted for an Open Chest Postsurgical Mycobacterium chimaera Infection Outbreak. Open Forum Infect. Dis. 2021, 8, ofab192. [CrossRef]

109. Götting, T.; Klassen, S.; Jonas, D.; Benk, C.; Serr, A.; Wagner, D.; Ebner, W. Heater-cooler units: Contamination of crucial devices in cardiothoracic surgery. J. Hosp. Infect. 2016, 93, 223-228. [CrossRef]

110. Kohler, P.; Kuster, S.; Bloemberg, G.; Schulthess, B.; Frank, M.; Tanner, F.C.; Rössle, M.; Böni, C.; Falk, V.; Wilhelm, M.J.; et al. Healthcare-associated prosthetic heart valve, aortic vascular graft, and disseminated Mycobacterium chimaera infections subsequent to open heart surgery. Eur. Heart J. 2015, 36, 2745-2753. [CrossRef] [PubMed]

111. Health Departments I NTM | HAI | CDC. Available online: https://www.cdc.gov/hai/organisms/ntm/health-departments. html (accessed on 6 September 2021).

112. Chand, M.; Lamagni, T.; Kranzer, K.; Hedge, J.; Moore, G.; Parks, S.; Collins, S.; Elías, C.D.O.; Ahmed, N.; Brown, T.; et al. Insidious Risk of Severe Mycobacterium chimaera Infection in Cardiac Surgery Patients. Clin. Infect. Dis. 2017, 64, 335-342. [CrossRef]

113. Sommerstein, R.; Schreiber, P.W.; Diekema, D.; Edmond, M.; Hasse, B.; Marschall, J.; Sax, H. Mycobacterium chimaera Outbreak Associated with Heater-Cooler Devices: Piecing the Puzzle Together. Infect. Control. Hosp. Epidemiol. 2017, 38, 103-108. [CrossRef] [PubMed]

114. Decalonne, M.; Lecorche, E.; Hau, E.; Petiteau, A.; Moreau, C.; Milan, O.; Lanotte, P.; Mereghetti, L.; Cambau, E.; Van Der Mee-Marquet, N. Cause Analysis of an Infection in Facelift Surgery Due to Mycobacterium chelonae. Front. Med. 2019, 6, 243. [CrossRef] 
115. Hammond, S.E.; Al-Bayati, A.; Joumblat, N.; Salgado, C.J. Mycobacterium chelonae Infection of the Buttocks Secondary to Lipofilling: A Case Report and Review of the Literature. Aesthetic Plast. Surg. 2017, 41, 1150-1154. [CrossRef] [PubMed]

116. Nascimento, H.; Viana-Niero, C.; Nogueira, C.L.; Bispo, P.; Pinto, F.; Uzam, C.D.P.P.; Matsumoto, C.K.; Machado, A.M.O.; Leao, S.; Hofling-Lima, A.L.; et al. Identification of the Infection Source of an Outbreak of Mycobacterium chelonae Keratitis After Laser in Situ Keratomileusis. Cornea 2018, 37, 116-122. [CrossRef]

117. Labuda, S.M.; Garner, K.; Cima, M.; Moulton-Meissner, H.; Halpin, A.L.; Charles-Toney, N.; Yu, P.; Bolton, E.; Pierce, R.; Crist, M.B.; et al. Bloodstream Infections with a Novel Nontuberculous Mycobacterium Involving 52 Outpatient Oncology Clinic Patients-Arkansas, 2018. Clin. Infect. Dis. 2020, 71, e178-e185. [CrossRef]

118. Philley, J.V.; Kannan, A.; Griffith, D.E.; Devine, M.S.; Benwill, J.L.; WallaceJr, R.J.; Brown-Elliott, B.A.; Thakkar, F.; Taskar, V.; Fox, J.G.; et al. Exosome secretome and mediated signaling in breast cancer patients with nontuberculous mycobacterial disease. Oncotarget 2017, 8, 18070-18081. [CrossRef]

119. Inkster, T.; Peters, C.; Seagar, A.; Holden, M.; Laurenson, I. Investigation of two cases of Mycobacterium chelonae infection in haemato-oncology patients using whole-genome sequencing and a potential link to the hospital water supply. J. Hosp. Infect. 2021, 114, 111-116. [CrossRef]

120. Yoshida, S.; Iwamoto, T.; Kobayashi, T.; Nomoto, R.; Inoue, Y.; Tsuyuguchi, K.; Suzuki, K. Two New Cases of Pulmonary Infection by Mycobacterium shigaense, Japan. Emerg. Infect. Dis. 2020, 26, 2728-2732. [CrossRef]

121. Brown-Elliott, B.A.; Woods, G.L. Antimycobacterial Susceptibility Testing of Nontuberculous Mycobacteria. J. Clin. Microbiol. 2019, 57, 834-853. [CrossRef]

122. de Moura, V.C.N.; Verma, D.; Everall, I.; Brown, K.P.; Belardinelli, J.M.; Shanley, C.; Stapleton, M.; Parkhill, J.; Floto, R.A.; Ordway, D.J.; et al. Increased Virulence of Outer Membrane Porin Mutants of Mycobacterium abscessus. Front. Microbiol. 2021, $12,1976$. [CrossRef] 